Marquette University

e-Publications@Marquette

Chemistry Faculty Research and Publications

Chemistry, Department of

$1-1-1978$

\title{
The Effect of Slow Two-Electron Transfers and Disproportionation on Cyclic Voltammograms
}

Michael D. Ryan

Marquette University, michael.ryan@marquette.edu

Published version. Journal of the Electrochemical Society, Vol. 125, No. 4 (1978): 547-555. DOI. (C) 1978 Electrochemical Society. Used with permission. 


\title{
The Effect of Slow Two-Electron Transfers and Disproportionation on Cyclic Voltammograms
}

\author{
Michael D. Ryan* \\ Marquette University, Department of Chemistry, Milwaukee, Wisconsin 53233
}

\begin{abstract}
The EE mechanism (two-electron transfer) for cyclic voltammetry was investigated in considerable detail along with the effect of disproportionation. The theory was developed for either the first or second electron transfer being slow while the other one was reversible. It was possible to develop generalized working curves for the height and shape of the wave regardless of the difference in $E^{\circ}$ 's and the values of $\alpha$ and $k_{\mathrm{s}}$. This theory was then applied to the analysis of the reduction of benzil in the presence of alkaline earth ions in dimethylformamide.
\end{abstract}

The theory for reversible and irreversible electron transfer has been examined in some detail previously for cyclic voltammetry (CV). The problem of multielectron transfers in CV was studied first by Polcyn and Shain (1). The main quantitative emphasis was placed on the deconvolution of separated waves and only qualitative results were given for multi-electron waves. Myers and Shain (2) were able to quantitatively correlate the shape and peak current function of reversible voltammetric waves to their difference in $E^{\circ}$ 's if the $E^{\circ}$ 's were close together. It was found that the shape of the wave was independent of the relative values of the $E^{\circ}$ 's only if the difference in $E^{\circ}$ 's was greater than $180 \mathrm{mV}$. Otherwise, the wave will be broader than expected, even though it is still reversible. In addition, its shape and position are independent of scan rate. No correlations were made for quasireversible or irreversible electron transfers.

Multi-electron transfers can put a much more stringent demand on the rate of electron transfers if the wave is shifted significantly from its $E^{\circ}$ because of the second electron transfer. Ruzic (3) has shown that, for polarography, the apparent heterogeneous electron transfer rate constant, $k_{\mathrm{s}}{ }^{\prime}$, for the over-all two-electron transfer is less than either of the individual rate constants, $k_{\mathrm{s}, 1}$ or $k_{s .2}$, if the second $E^{\circ}, E_{2}$, is more positive than the first $E^{\circ}, E_{1}$. In particular, the rate constant that is calculated using conventional theory is not the individual rate constant but an apparent one. Thus, the theory for quasireversible electron transfers in $\mathrm{CV}$ (4) yields the value of $k_{\mathrm{s}}$ '.

Competing with the multielectron transfer mechnism is the disproportionation mechanism. If the second electron transfer is so slow as to not be important and if $E_{2}$ is positive of $E_{1}$, the classical disproportionation mechanism can then occur. The theory for this mechanism has been developed and verified by Saveant (5). But very little work has been done in trying to assess the relative importance of the electron transfer mechanism (EE) as compared to the disproportionation (DISP) mechanism. For reversible electron transfers the cyclic voltammograms will not distinguish between these two mechanisms.

It is the purpose of this work to develop the cyclic voltammetric theory more generally for the EE mechanism, including the possibility of disproportionation, and to verify it experimentally. The emphasis will be placed on those cases where only one wave is observed, and either the first or second electron transfer is slow. Recent studies have shown several reductions that are now known to follow the EE mechanism (6). In this study, the electrochemical reduction of benzil in dimethylformamide (DMF) in the presence of alkaline

*lectrochemical Society Active Member. Key words: EE mechanism, cyclic voltammetry, disproportion- earth salts, which is known to be a quasireversible two-electron transfer $(6)$, is investigated in more detail in this work using the theory that is presented.

\section{Experimental}

Spectroquality $\mathrm{N}, \mathrm{N}$-dimethylformamide was obtained from Matheson, Coleman, and Bell. The solvents were dried as required using activated molecular sieves. Strontium and barium perchlorate were obtained from G. F. Smith Chemical Company and were vacuum dried at $250^{\circ} \mathrm{C}$ for $6 \mathrm{hr}$ (7). Benzil was recrystallized from ethanol. The reference electrode is the same as was described in Ref. (6). Positive feedback resistance compensation was used in all of the fast scan rate experiments. A hanging mercury drop electrode was used as the working electrode. All solutions were deaerated with dry nitrogen. The diffusion equations were solved numerically using the technique of digital simulation (8). The flux equations for a two-electron transfer that were derived by Feldberg (9) were used to calculate the current.

\section{Theory}

The generalized EE mechanism that is discussed in this paper is given by reactions [1]-[3]

$$
\begin{gathered}
\mathrm{A}+e \stackrel{E_{1}}{\rightleftharpoons} \mathrm{B} \\
\mathrm{B}+e \stackrel{E_{2}}{\rightleftharpoons} \mathrm{C} \\
\stackrel{k_{\mathrm{d}}}{\rightarrow} \mathrm{A}+\mathrm{C}
\end{gathered}
$$

Each electron transfer has associated with it a $k_{\mathrm{s}, \mathrm{i}}$ and $\alpha_{i}$ value, where $i=1$ or 2 , for the first or second electron transfer, respectively. The analysis of the mechanism is divided into two major sections, depending upon whether the first or second electron transfer is rate limiting. In both cases, the mechanism is studied in the regions where only one wave is seen.

While each individual step has an $\alpha_{i}$ associated with it, the over-all electron transfer coefficient that is observed if one wave is seen has been derived by Mohilner (10). If the first electron transfer is limiting, then

$$
\alpha n=\alpha_{1}
$$

If the second electron transfer step is limiting, the observed $\alpha n$ is

$$
\alpha n=1+\alpha_{2}
$$

First-electron transfer limiting.-Reversible electron transfer.-Using the theory that was derived for polarography (3) and verified by digital simulation in this work for $\mathrm{CV}$, the value of $k_{\mathrm{s}}^{\prime}$ can be calculated as follows

$$
k_{s}^{\prime}=k_{\mathrm{s}, 1} \exp \left[-\alpha_{1} \mathbf{F} \Delta E / 2 R T\right]
$$


where $\Delta E=E_{2}-E_{1}$. As stated earlier, it is the $k_{\mathrm{s}}^{\prime}$ value that is experimentally measured. Thus, $\alpha_{1}$ and $\Delta E$ must be known in order to calculate $k_{5,1}$. In order to generalize the results, the dimensionless electron transfer rate parameter, $\psi$, will be used and is defined as follows

and

$$
\psi=k_{\mathrm{s}} / \sqrt{\pi a D_{\mathrm{A}}}
$$

$$
a=n \mathbf{F} v / R T
$$

where $v$ is the scan rate and the other terms have either been defined or have their usual electrochemical significance. Combining Eq. [6] and [7], we obtain

$$
\psi_{1}^{\prime}=\psi_{1} \exp \left[\frac{-\alpha_{1} \mathbf{F} \Delta E}{2 R T}\right]
$$

The shape of the cyclic voltammogram depends on its reversibility $\left(\psi_{1}^{\prime}\right)$ and on the difference in $E^{\circ}$ 's $(\Delta E)$. These are two different parameters which must be evaluated separately. Cyclic voltammograms can be divided into three general classes depending on the value of $\psi_{1}{ }^{\prime}$. These classes are: (i) reversible, $\psi_{1}^{\prime}>7$, (ii) quasireversible, $0.1<\psi_{1}^{\prime}<7$; and (iii) irreversible, $\psi_{1}{ }^{\prime}<0.1$. Within these three classes, the shape of the wave is also dependent upon $\Delta E$. In this paper, for each of the three classes, the effect of $\Delta E$ on these classes is examined. Several limiting cases have already been described. For the reversible and irreversible classes, Nicholson and Shain (11) have derived the shape and behavior of the wave if $\Delta E>180$ $\mathrm{mV}$. Myers and Shain (2) and Polcyn and Shain (1) have investigated the reversible case if $\Delta E<180 \mathrm{mV}$. These papers can be consulted to determine the shape of the wave and the value of $\Delta E$. The irreversible case was also studied by Polcyn and Shain (1) for $\Delta E<$ $180 \mathrm{mV}$ but quantitative analysis was possible only if two waves were seèn.

The disproportionation reaction (reaction [3]) has no effect on the shape of the wave if the first electron transfer is the slow step. This is because B is rapidly reduced to $C$ at the electrode surface. This is not to say that the disproportionation reaction does not occur but only that the reaction has no effect on the wave when it occurs in this situation. This was verified by digital simulation.

Quasireversible electron transfer.-For quasireversible electron transfers, the shape of the wave depends upon $\psi_{1}^{\prime}$ and $\Delta E$, and is not very dependent upon $\alpha_{1}$. If $\Delta E$ is larger than $180 \mathrm{mV}$, the value of $k_{\mathrm{s}}$ ' can be calculated from the theory for quasireversible waves given by Nicholson (4). But even for $\Delta E>180 \mathrm{~m}$, noticeable deviations occur when the waves are simulated by the digital simulation technique $(8,9)$. The results are shown in Table I for $\psi_{1}^{\prime}$ less than 1 . The deviations are due to the greater effect of $\alpha_{1}$ on the peak potentials for the same value of $\psi$.

To calculate $k_{\mathrm{s}, 1}, \Delta E$ and $\alpha_{1}$ must be known. The value of $\alpha_{1}$ cannot be accurately determined unless scan rates large enough to make the wave irreversible are used. At these large scan rates, the theory presented in the next subsection on irreversible electron transfers can be used to calculate $\alpha_{1}$. The value of $\Delta E$ can be calculated using the reversible theory if slow enough scan rates can be achieved or by using the irreversible theory that is described for fast scan rates.

\begin{tabular}{|c|c|c|}
\hline \multicolumn{3}{|c|}{$\Delta E_{\mathfrak{p}}(\mathrm{mV})$} \\
\hline$\psi_{1}^{\prime}$ & $\begin{array}{l}\text { EE mech- } \\
\text { anism }\end{array}$ & Ref. (4) \\
\hline $\begin{array}{l}1.0 \\
0.5 \\
0.2 \\
0.1\end{array}$ & $\begin{array}{r}45 \\
61 \\
107 \\
156\end{array}$ & $\begin{array}{r}42 \\
53 \\
79 \\
106\end{array}$ \\
\hline
\end{tabular}
For $\Delta E$ values less than $180 \mathrm{mV}$, the working curve

Table I. Variation of $\Delta E_{p}$ values as a function of $\psi_{1}^{\prime}\left(\alpha_{1}=0.5\right)$ will depend upon $\Delta E$ in addition to $\psi_{1}^{\prime}$. This effect is not large and can be corrected for in the same way as shown in Eq. [32] later in this paper.

Irreversible electron transfer.-In the case where single scan is used, the position, shape, and size of the reduction wave depends on the value of $\psi_{1}^{\prime}, \alpha_{1}$, and $\Delta E$. The wave does not occur at its thermodynamically defined $E^{\circ}$ but at a more negative potential depending upon scan rate. In the theory as derived by Nicholson and Shain (11) for multielectron irreversible transfer, it was assumed that all the electron transfers except the slow one were fast, at least at the potentials where the reduction wave occurs. Polcyn and Shain (1) have shown that the wave will be affected if this assumption does not hold true but no quantitative theory was derived if one wave is observed. In order to provide a quantitative measure of the relative difference in reduction potentials, the parameter, $\Delta E_{\mathrm{AB}}$, is defined as

$$
\Delta E_{\mathrm{AB}}=\Delta E-\frac{59}{\alpha_{1}} \log \psi_{1}
$$

This equation is derived from the fact that an irreversible reduction is shifted to more negative potentials by a rate of $59 / \alpha_{1} \log \psi_{1}$. This parameter corrects $\Delta E$ for the fact that irreversible reductions do not occur at their thermodynamically defined potential but at some more negative potential depending upon $\alpha_{1}$ and $k_{\mathrm{s}_{1} 1}$. Similar to reversible electron transfer, only one wave is seen if $\Delta E_{A B}$ is positive and two waves are seen if $\Delta E_{\mathrm{AB}}$ is negative enough. The exact values of these regions are shown later. By combining Eq. [9] and [10], $\Delta E_{\mathrm{AB}}$ can be defined in terms of $\psi_{1}^{\prime}$, which is experimentally measured

$$
\Delta E_{\mathrm{AB}}=\Delta E / 2-\frac{59}{\alpha_{1}} \log \psi_{1}^{\prime}
$$

By using digital simulation (8), it was found that the theory for irreversible electron transfers derived by Nicholson and Shain (11) can be used if $\Delta E_{\mathrm{AB}}$ is greater than $75 / \alpha_{1} \mathrm{mV}$. In this case, the following diagnostic criteria for the cathodic peak potential, $E_{p e}$, the cathodic peak current, $i_{\mathrm{pc}}$, and the peak $E_{\mathrm{pp} / 2}$ values can be calculated

$$
\begin{gathered}
i_{\mathrm{pc}}=0.992 \mathrm{FAC}_{\mathrm{A}} * \sqrt{\alpha_{1} \mathrm{D}_{\mathrm{A}} a_{1}} \\
E_{\mathrm{pp} / 2}=E_{\mathrm{pc}}-E_{\mathrm{p} / 2}=47.7 / \alpha_{1} \mathrm{mV} \\
d E_{\mathrm{pc}} / d \log v=30 / \alpha_{1} \mathrm{mV}
\end{gathered}
$$

and

$$
a_{1}=\mathbf{F} v / R T
$$

and where $E_{p / 2}$ is the half-peak potential.

If $\Delta E_{\mathrm{AB}}$ is less than $75 / \alpha_{1} \mathrm{mV}$ and only one wave is seen, the shape of the wave is changed from that predicted for an irreversible electron transfer and depends upon the scan rate. This is shown in Fig. 1 for three ditferent values of $\Delta E_{\mathrm{AB}}$. As the scan rate is increased ( $\Delta E_{\mathrm{AB}}$ larger), the value of $\Delta E_{\mathrm{AB}}$ will increase so as to make the wave approach the irreversible theory as given in Eq. [12]-[14]. The $E_{\mathrm{pp} / 2}$ value is most strongly dependent upon $\Delta E_{\mathrm{AB}}$ for $\Delta E_{\mathrm{AB}}$ values less than $75 / \alpha_{1}$ $\mathrm{mV}$. The variation of $E_{\mathrm{pp} / 2}$ values with $\Delta E_{\mathrm{AB}}$ is shown in Fig. 2 for various values of $\alpha_{1}$, where the $E_{\mathrm{pp} / 2}$ values have been normalized in the following manner

$$
E^{*}{ }_{\mathrm{pp} / 2}=\alpha_{1} E_{\mathrm{pp} / 2}
$$

For large negative values of $\Delta E_{\mathrm{AB}}$ two waves are seen and each wave can be analyzed individually because $A$ will reduce prior to the potential for the $B$ wave. For intermediate values of $\Delta E_{\mathrm{AB}}$, the $\mathrm{A}$ reduction wave will overlap the $B$ wave and hence a broaden wave will be seen. There is a maximum value for which $\Delta E$ can have and still see the behavior as described in Fig. 2. For the wave to begin to broaden, $\Delta E_{\mathrm{AB}}$ must be less than $75 / \alpha_{1} \mathrm{mV}$ and $\psi_{1}^{\prime}$ must be less than 0.1 . Thus, rearranging Eq. [11], we obtain 


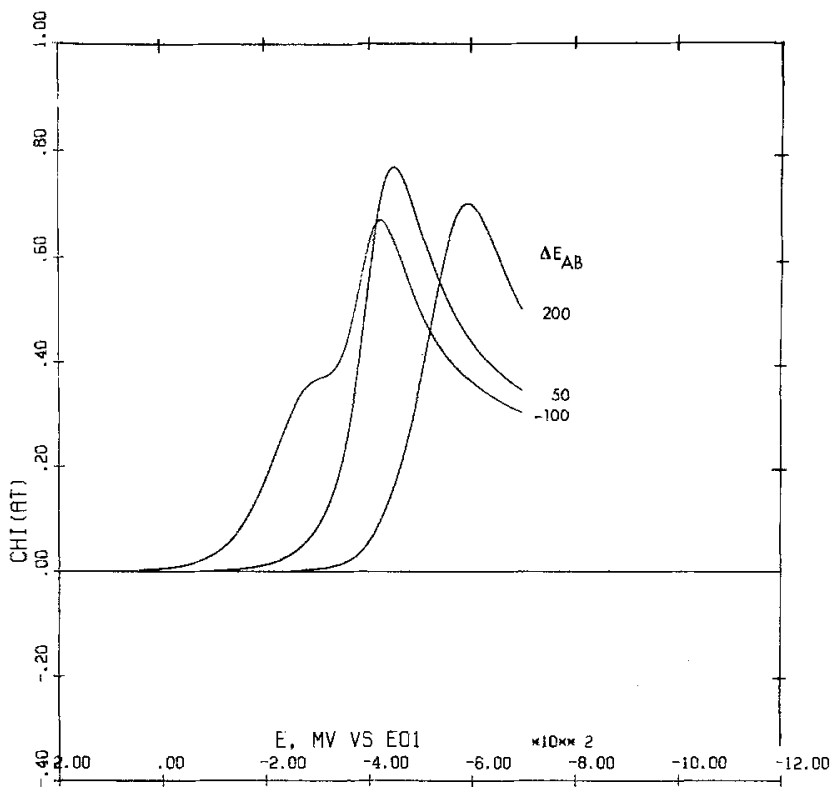

Fig. 1. The simulated cathodic scan for three different values of $\Delta E_{\mathrm{AB}}$ (first-electron transfer irreversible).

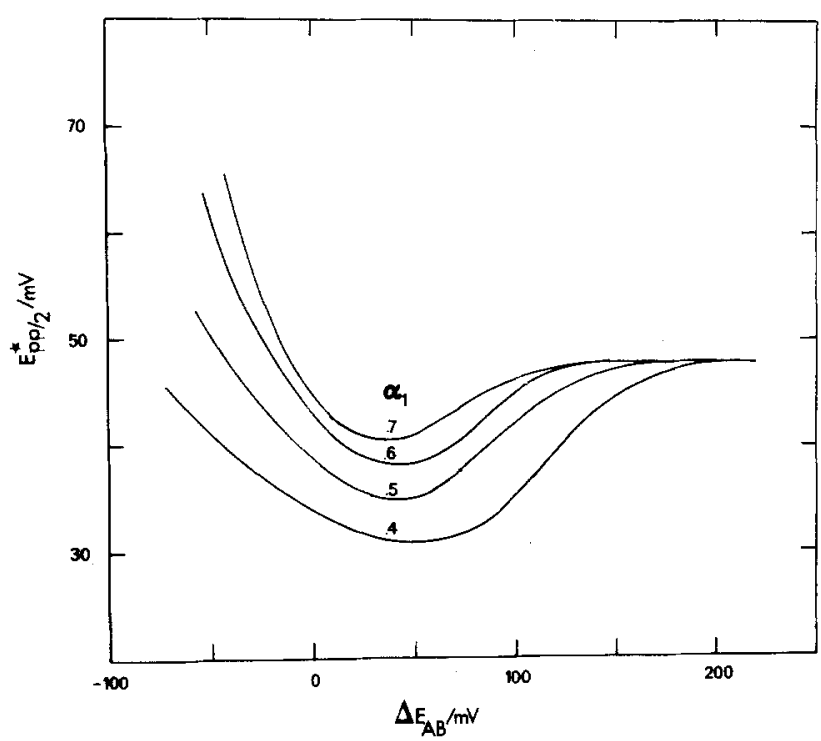

Fig. 2. The variation of $E_{\mathrm{pp} / 2}{ }^{*}$ as o function of $\Delta E_{\mathrm{AB}}$ for various volues of $\alpha_{1}$ in the case where the first electron tronsfer is irreversible.

$$
\Delta E<\frac{32}{\alpha_{1}} \mathrm{mV}
$$

Otherwise, Eq. [12]-[14] will always hold when the wave is irreversible. In the limit of very slow scan rates, the $E_{\mathrm{pp} / 2}$ value is limited by the value derived by Myers and Shain (2). The peak current function goes through a maximum at the same point that the $E_{\mathrm{pp} / 2}$ values go through a minimum but the change in this parameter is not very large with the maximum change on the order of $20 \%$, making this parameter less useful.

In the cyclic experiment, on the anodic scan, the reverse of reactions [1] and [2] occurs

$$
\begin{aligned}
& \mathrm{C} \stackrel{E_{2}}{\rightleftharpoons} \mathrm{B}+e \\
& \mathrm{~B} \stackrel{E_{1}}{\rightleftharpoons} \mathrm{A}+e
\end{aligned}
$$

For the return peak, reaction [19] is rate limiting, which is the second-electron transfer. A full discussion of this case is given in the next section and only a few pertinent details are given here. Either one or two waves can be seen on the return scan. The experimental conditions for the number of peaks that are seen are given in the next section.

With the information from the reverse scan, it is possible to determine all the parameters for the twoelectron transfer. There are four unknowns which need to be evaluated from the experimental data. They are: $E_{1}, E_{2}, k_{\mathrm{s}, 1}$ and $\alpha_{1}$. There are two other parameters that are related to these and are calculated during the analysis. They are

$$
E_{1,2}=\left(E_{1}+E_{2}\right) / 2
$$

and $\Delta E$. It is the aim of the rest of this section to develop the equations necessary to calculate these parameters from the data.

If two anodic peaks are seen, $E_{2}$ can be found directly from the most negative peak potential, $E_{\mathrm{pa}(2)}$, because that wave will occur at its thermodynamically defined potential

$$
E_{2}=E_{\mathrm{pa}(2)}-0.0285
$$

The value of $\alpha_{1}$ can be determined from several methods depending on the value of $\Delta E_{\mathrm{AB}}$. If Eq. [12]-[14] are obeyed, $\alpha_{1}$ can be determined from the shift in $E_{\mathrm{pc}}$ or by the $E_{\mathrm{pp} / 2}$ value. If $\Delta E_{\mathrm{AB}}$ is less than $75 / \alpha_{1} \mathrm{mV}$ (in other words, the shape depends upon scan rate), the value of $\alpha_{1}$ can be determined from the more positive anodic peak potential, $\boldsymbol{E}_{\mathrm{pa}(1)}$. Thus

$$
\frac{d E_{\mathrm{pa}(1)}}{d \log v}=\frac{30}{1-\alpha_{1}} \mathrm{mV}
$$

The cathodic peak potential can be related to the $E_{1,2}$ value by the following equation (11) if $\Delta E_{\mathrm{AB}}>$ $75 / \alpha_{1} \mathrm{mV}$

$$
E_{\mathrm{pc}}=E_{1,2}-\frac{R T}{\alpha_{1} \mathbf{F}}\left(0.339-\log \psi_{1}^{\prime}+\sqrt{\frac{\alpha_{1}}{2 \pi}}\right)
$$

and $E_{\mathrm{pa}(1)}$ is

$$
\begin{aligned}
E_{\mathrm{pa}}=E_{1,2}+\frac{R T}{\left(1-\alpha_{1}\right) \mathbf{F}}\left(\begin{array}{l}
0.339-\log \psi_{1}^{\prime} \\
\left.+\log \sqrt{\frac{1-\alpha_{1}}{\pi}}\right)
\end{array}\right.
\end{aligned}
$$

By taking the difference in the peak potentials, we obtain

$$
\begin{aligned}
& \Delta E_{\mathrm{p}}=\frac{0.059}{\alpha_{1}\left(1-\alpha_{1}\right)}\left(0.339-\log \psi_{1}^{\prime}\right) \\
& \quad+\frac{0.059}{1-\alpha_{1}} \log \sqrt{\frac{1-\alpha_{1}}{\pi}}+\frac{0.059}{\alpha_{1}} \log \sqrt{\frac{\alpha_{1}}{2 \pi}}
\end{aligned}
$$

Thus, since $\alpha_{1}$ is known, $\psi_{1}^{\prime}$ can be calculated from the $\Delta E_{\mathrm{p}}$ values. If $\psi_{1}^{\prime}$ is now substituted in Eq. [23], $E_{1,2}$ can be found. The value of $E_{2}$ is known from Eq. [21] so $E_{1}$ can be calculated by using Eq. [20].

If only one anodic peak is seen, $\alpha_{1}$ can be found from the anodic or cathodic wave. If the anodic peak potential is used to calculate $\alpha_{1}$, then as will be described in the next section, Eq. [26] must be used

$$
\frac{d E_{\mathrm{pa}}}{d \log v}=30 /\left(2-\alpha_{1}\right) \mathrm{mV}
$$

The value of $\psi_{1}^{\prime}$ can be found, as before, from the $\Delta E_{\mathrm{p}}$ value but Eq. [28] must be used because $E_{p a}$ is given by

$$
E_{\mathrm{pa}}=E_{1,2}+\frac{0.059}{2-\alpha_{1}}\left[0.339+\log \psi_{1}^{\prime}+\log \sqrt{\frac{1-\alpha_{1}}{2 \pi}}\right]
$$

Using Eq. [27], the variation of $\Delta E_{p}$ with $\psi_{1}^{\prime}$ is given by 


$$
\begin{aligned}
& \Delta E_{\mathrm{p}}=\frac{0.118}{\alpha_{1}\left(2-\alpha_{1}\right)}\left(0.339+\log \psi_{1}^{\prime}\right) \\
& +\frac{0.059}{2-\alpha_{1}} \log \sqrt{\frac{1-\alpha_{1}}{2 \pi}}+\frac{0.059}{\alpha_{1}} \log \sqrt{\frac{\alpha_{1}}{2 \pi}}
\end{aligned}
$$

The value of $E_{1,2}$ can be found from Eq. [23]. The final problem is to find a method to determine $E_{1}$ and $E_{2}$ from $E_{1,2}$. To do this, either fast or slow scan rates must be used to separate either the anodic or cathodic peaks into two waves. It is theoretically possible to cause the cathodic peak to split apart if $\Delta E$ is less than $-60 \mathrm{mV}$. If this is not possible, then scan rates fast enough to split the anodic peak apart must be used. If the cathodic peak begins to split apart, Fig. 2 can be used to calculate the value of $\Delta E_{\mathrm{AB}}$ from the $E_{\mathrm{pp} / 2}$ values. From Eq. [11], it is possible to determine $\Delta E$ because $\alpha_{1}$ and $\psi_{1}^{\prime}$ are known

$$
\Delta E=2\left(\Delta E_{\mathrm{AB}}+\frac{59}{\alpha_{1}} \log \psi_{1^{\prime}}\right)
$$

Unless there is some change in the shape of either the anodic or cathodic wave it is impossible to determine $E_{1}$ and $E_{2}$.

Second-electron transfer limiting.-No disproportionation. - If the disproportionation reaction (reaction [3]) does not occur, the only way of producing $\mathrm{C}$ is by the direct reduction of $B$ at the electrode surface. As with the previous case, an apparent electron transfer rate constant, $k_{s}^{\prime}$, is observed experimentally rather than the actual $k_{s}$ value of the second step. The value of $k_{\mathrm{s}}{ }^{\prime}$ is given by

or

$$
k_{\mathrm{s}}{ }^{\prime}=k_{\mathrm{s}, 2} \exp \left(-\left(1-\alpha_{2}\right) \frac{\mathbf{F}}{R T} \frac{\Delta E}{2}\right)
$$

$$
\psi_{2}^{\prime}=\psi_{2} \exp \left[-\left(1-\alpha_{2}\right) \frac{\mathbf{F}}{R T} \frac{\Delta E}{2}\right]
$$

As before, reversible behavior is observed if $\psi_{2}{ }^{\prime}$ is greater than 7 . If $\psi_{2}^{\prime}$ is less than 0.1 , an irreversible wave is seen. For reversible waves, the shape of the wave (2) depends only on $\Delta E$ and is independent of $\Delta E$ if $\Delta E$ is greater than $180 \mathrm{mV}$.

Quasireversible electron transfer.-For quasireversible waves, the shape of the wave depends upon $\psi_{2}^{\prime}$ and $\Delta E$ and is not very dependent upon $\alpha_{2}$. If $\Delta E$ is larger than $180 \mathrm{mV}$ and $\psi_{2}^{\prime}$ greater than 0.5 , the value of $k_{s}^{\prime}$ can be calculated from the theory for quasireversible waves given by Nicholson (4). The $\Delta E_{\mathrm{p}}$ values as calculated by digital simulation for different $\alpha_{2}$ values are given in Table II for several $\psi_{2}^{\prime}$ values less than 1.

If $\Delta E$ is less than $180 \mathrm{mV}$, the $\Delta E_{\mathrm{p}}$ values are larger than predicted by Ref. (4). To a close approximation, the working curves for $\Delta E<180 \mathrm{mV}$ can be obtained by adding the excess broadness, $E_{\text {exc }}$, as defined in Eq. [32] to the data in Table II

$$
E_{\text {exc }}=\Delta E_{\text {pr }}-29 \mathrm{mV}
$$

\begin{tabular}{|c|c|c|c|c|c|}
\hline$\psi a^{\prime}$ & $\alpha_{2}=$ & 0.35 & $\Delta E_{D}(\underset{0.5}{(\mathrm{mV})}$ & 0.65 & Ref. (4) \\
\hline $\begin{array}{l}1.0 \\
0.5 \\
0.2 \\
0.1\end{array}$ & & $\begin{array}{r}44 \\
58 \\
\mathbf{9 1} \\
\mathbf{1 2 8}\end{array}$ & $\begin{array}{r}44 \\
56 \\
88 \\
\mathbf{1 3 5}\end{array}$ & $\begin{array}{r}43 \\
53 \\
85 \\
147\end{array}$ & $\begin{array}{r}42 \\
53 \\
79 \\
106\end{array}$ \\
\hline
\end{tabular}

where $\Delta E_{\mathrm{pr}}$ is the $\Delta E_{\mathrm{p}}$ value for a given $\Delta E$ (reversible case).

Irreversible case.-With a single scan, as defined earlier, the wave is irreversible if $\psi_{2}^{\prime}$ is less than 0.1 .

Table II. Variation of $\Delta E_{\mathrm{p}}$ values as o function of $\psi_{2}^{\prime}$
Irreversibility of the second electron transfer makes the second electron transfer occur at more negative potentials. In order to correct for this, we can detine a parameter, $\Delta E_{\mathrm{BC}}$, which takes into account the effect of the slow electron transfer

$$
\Delta E_{\mathrm{BC}}=\Delta E / 2+\frac{59}{1+\alpha_{2}} \log \psi_{2}^{\prime}
$$

This parameter normalizes the combined effects of $\Delta E$ and $\psi_{2}^{\prime}$ on the relative positions of the two waves. From digital simulation, it was found that, if $\Delta E_{B C}$ is greater than $50 \mathrm{mV}$, the shape of the wave is given by the theory derived by Nicholson and Shain (11). Substituting $n=2$ and $\alpha n=1+\alpha_{2}$, the following diagnostic parameters can be calculated

$$
\begin{gathered}
i_{\mathrm{p}}=0.992 \mathrm{FA} \sqrt{\left(1+\alpha_{2}\right) D a_{1} C_{\mathrm{A}}{ }^{*}} \\
E_{\mathrm{pp} / 2}=47.7 /\left(1+\alpha_{2}\right) \mathrm{mV} \\
d E_{\mathrm{p}} / d \log v=30 /\left(1+\alpha_{2}\right) \mathrm{mV}
\end{gathered}
$$

If $\Delta E_{\mathrm{BC}}$ is less than $50 \mathrm{mV}$ the wave will broaden and the peak current function will decrease. This effect can be seen in Fig. 3 for three different values of $\Delta E_{\mathrm{BC}}$. The variation in $\chi_{\mathrm{p}}$ and $E_{\mathrm{pp} / 2}$ values can be calculated as a function of $\alpha_{2}$ by the following normalizations

$$
\begin{gathered}
\chi_{\mathrm{p}}{ }^{*}=\chi_{\mathrm{p}} /\left(1+\alpha_{2}\right)^{1 / 2} \\
E_{\mathrm{pp} / 2^{*}}=E_{\mathrm{pp} / 2}\left(1+\alpha_{2}\right)
\end{gathered}
$$

The effect of $\Delta E_{\mathrm{BC}}$ on $\chi_{\mathrm{p}}{ }^{*}$ and $E_{\mathrm{pp} / 2}{ }^{*}$ is shown in Fig. 4 and 5 . The variations in these parameters are qualitatively similar to the ECE and DISP mechanisms. It is only at fast scan rates that the $\chi_{\mathrm{p}}$ and $E_{\mathrm{pp} / 2}$ values differ significantly from the ECE and DISP mechanism. But chronoamperometry will easily distinguish between these mechanisms because a two-electron diffusion-controlled wave can be obtained if a negative enough potential is used. In contrast, an ECE or DISP mechanism will show the slow kinetic step regardless of applied potential.

In a cyclic experiment, since the $B$ to $C$ reduction is limiting in this case, the $\mathrm{C}$ to $\mathrm{B}$ oxidation will be limiting on the reverse scan. Thus, the theory for the first-step limiting must be used to evaluate the oxidation peak.

As before, there are four parameters which must be determined: $E_{1}, E_{2}, k_{\mathrm{s}, 2}$, and $\alpha_{2}$. Thus, four indepen-

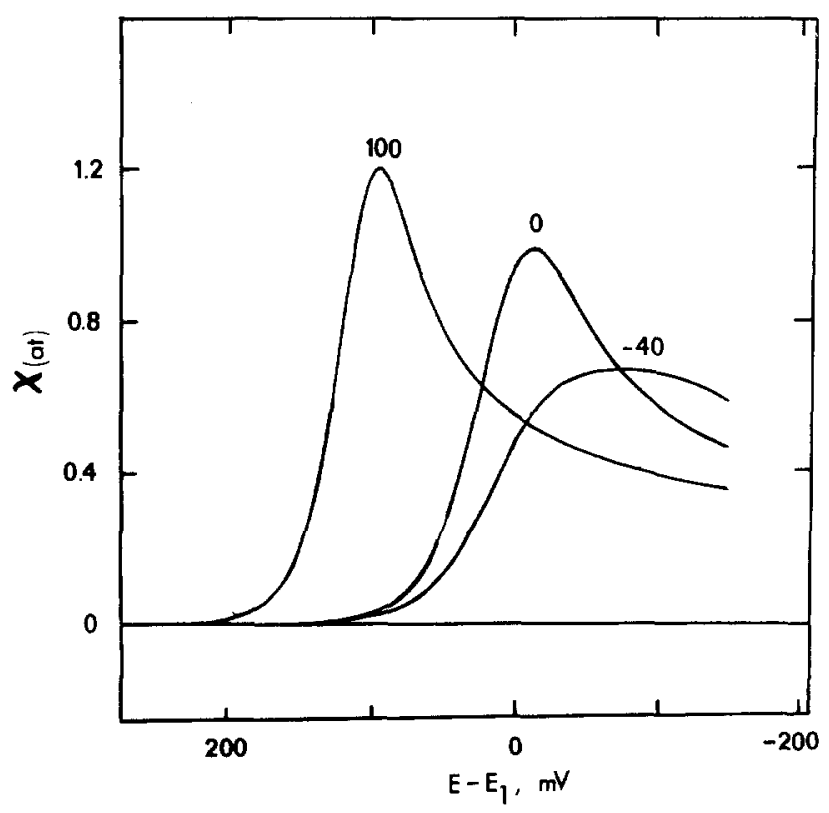

Fig. 3. The simulated cathodic scan for three different values of $\Delta E_{\mathrm{BC}}$ (second-electron transfer irreversible). 


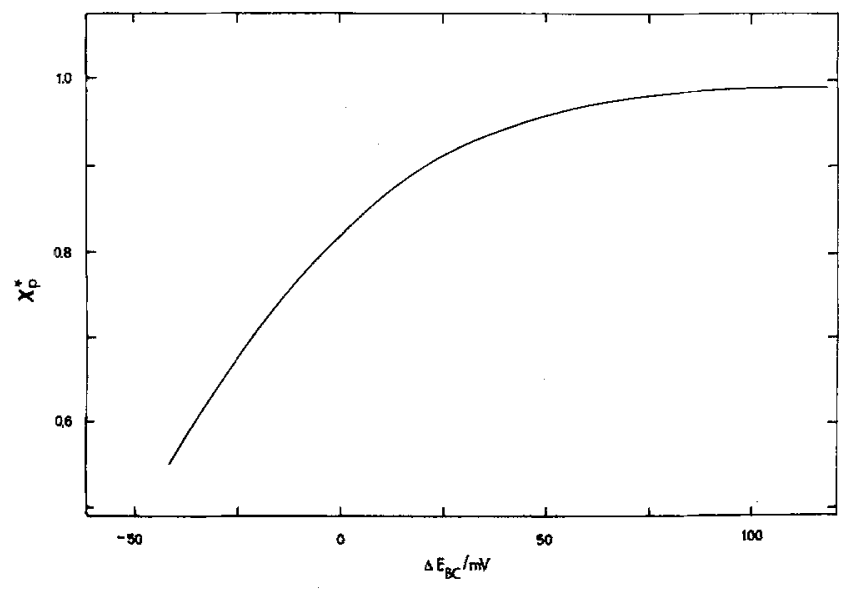

Fig. 4. The variation of $\chi_{\mathrm{p}}{ }^{*}$ as a function of $\Delta E_{\mathrm{BC}}$ for the case where the second electron transfer is irreversible.

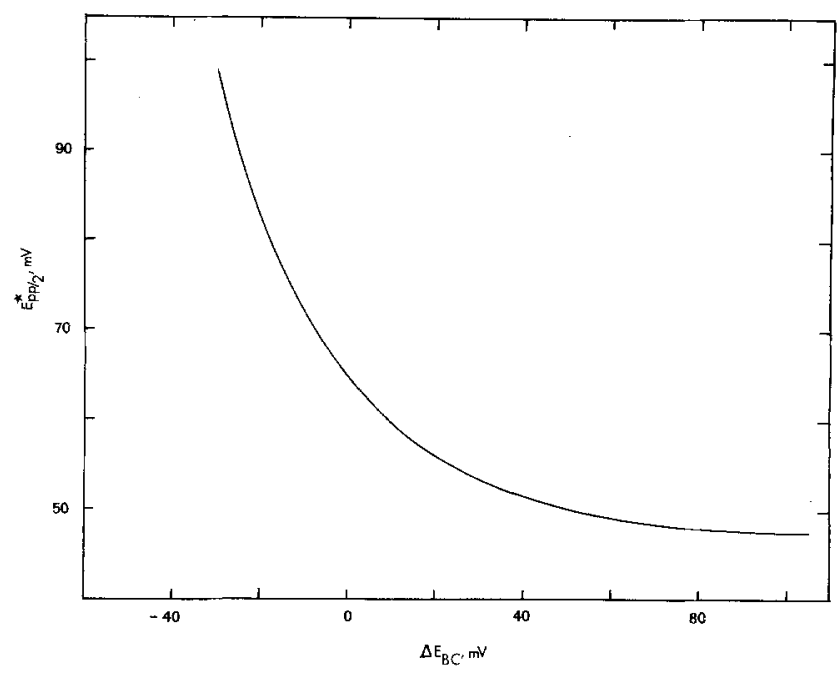

Fig. 5. The variation of $E_{\mathrm{pp}} / 2^{*}$ as a function of $\Delta E_{\mathrm{BC}}$ for the case where the second electron transfer is irreversible.

dent equations must be derived. Only one anodic peak can be seen under practically any conditions where only one cathodic peak is seen as a consequence of Eq. [17]. This limits the existence of two peaks to $\Delta E$ values which are close to zero or negative. The value of $\alpha_{2}$ can be calculated from Eq. [35] or [36]. The second equation that can be used to calculate these parameters is the cathodic peak potential (11), which is

$E_{\mathrm{pc}}=E_{1,2}-\frac{0.059}{1+\alpha_{2}}\left[0.339-\log \psi_{2}^{\prime}+\log \sqrt{\frac{\alpha_{2}}{2 \pi}}\right]$

In addition, $E_{\mathrm{pa}}$ is given by (11)

$E_{\mathrm{pa}}=E_{1,2}+\frac{0.059}{1-\alpha_{2}}\left[0.339-\log \psi 2^{\prime}+\log \sqrt{\frac{1-\alpha_{2}}{2 \pi}}\right]$

Combining Eq. [39] and [40], the $\Delta E_{\mathrm{p}}$ values can be derived as a function of $\psi_{2}^{\prime}$

$$
\begin{array}{r}
\Delta E_{\mathrm{p}}=\frac{0.118}{1-\alpha_{2}}\left(0.339-\log \psi_{2}{ }^{\prime}\right)+\frac{0.059}{1+\alpha_{2}} \log \sqrt{\frac{\alpha_{2}}{2 \pi}} \\
+\frac{0.059}{1-\alpha_{2}} \log \sqrt{\frac{1-\alpha_{2}}{2 \pi}}
\end{array}
$$

Once $\psi_{2}^{\prime}$ is calculated, $E_{1,2}$ can be calculated from Eq. [39]. The final determination of $E_{1}$ or $E_{2}$ requires that $\Delta E_{\mathrm{BC}}$ be less than $50 \mathrm{mV}$ so that the wave will begin to split apart. If $\Delta E_{\mathrm{BC}}$ can be determined from the $E_{\mathrm{pp} / 2}$ or $\chi_{\mathrm{p}}$ values, then

$$
\Delta E=2\left(\Delta E_{\mathrm{BC}}-\frac{59}{1+\alpha_{2}} \log \psi_{2}^{\prime}\right)
$$

If $\Delta E$ is such that the wave does not begin to split apart, then a lower limit on $\Delta E$ can be established because $\Delta E_{\mathrm{BC}}$ must be greater than $50 \mathrm{mV}$

$$
\Delta E>100-\frac{118}{1+\alpha_{2}} \log \psi_{2}^{\prime}
$$

Thus, from Eq. [35] or [36], [39], and [41] and [42], we have four independent equations which allow one to calculate $k_{\mathrm{s}, 2}, \alpha_{2}, E_{1}$ and $E_{2}$. The solution is simple because there is only one new unknown in each equation. It is important to obtain a good determination of $\alpha_{2}$ since this is critical in all the equations. If the wave is beginning to split apart, it is probably more accurate to use the anodic peak potential to determine $\alpha_{2}$ because that will not be affected. But fortunately, it turns out that unless the wave has broadened considerably, the calculation of $\alpha_{2}$ from Eq. [36] is also not seriously affected even though Eq. [35] cannot be used.

Disproportionation.-For $\Delta E>0$, the disproportionation reaction is favorable and can compete with the electron transfer if it is fast enough. In order to discuss this mechanism quantitatively, the rate constant, $k_{d}$, is normalized as follows

$$
\lambda_{\mathrm{d}}=k_{\mathrm{d}} \mathrm{C}_{\mathrm{A}} * / a
$$

where $\lambda_{d}$ is the disproportionation kinetic parameter. It is important to keep in mind that $\lambda_{\mathrm{d}}$ depends upon $C_{A}{ }^{*}$ while $\psi_{2}$ does not. Thus, it is possible to change $\lambda_{d}$ without changing $\psi_{2}$ at the same time. In Fig. 6, the effect of the disproportionation reaction can be seen quite clearly. In this figure, the wave becomes dependent upon the disproportionation reaction and not on the second electron transfer. The same type of behavior is demonstrated in Fig. 7, where the electron transfer predominates if it is large enough in spite of a fairly significant rate for the disproportionation reaction. Qualitatively, the DISP mechanism is most important for negative values of $\Delta E_{\mathrm{BC}}$. If $\Delta E_{\mathrm{BC}}$ is positive, the difference in the shape and height of the wave due to these two mechanisms is not large.

The effect of the disproportionation reaction on the $\mathrm{EE}$ mechanism was determined by the use of digital simulation (8). The results are shown in Fig. 8 and 9 for the $\chi_{\mathrm{p}}$ and $E_{\mathrm{pc}}$ values for $\alpha_{2}=0.5$ as a function of $\Delta E_{\mathrm{BC}}$. It is assumed in this case that the wave is ir-

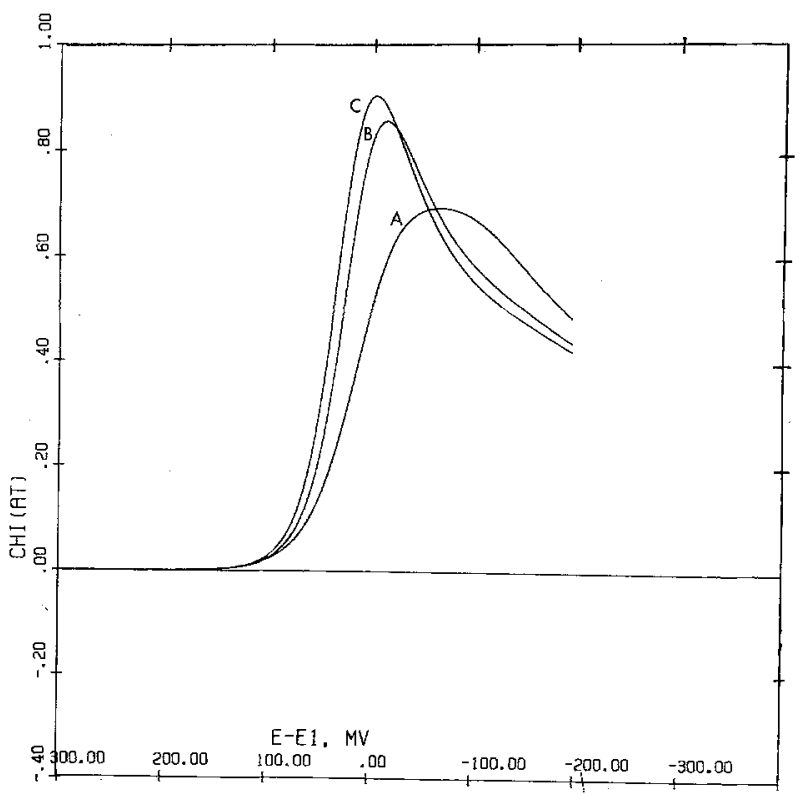

Fig. 6. The simulated cathodic scan for $\Delta E_{\mathrm{BC}}=-20 \mathrm{mV}$ and (a) $\lambda_{\mathrm{d}}=0$; (b) $\lambda_{\mathrm{d}}=10$; and (c) $\lambda_{\mathrm{d}}=30$. 


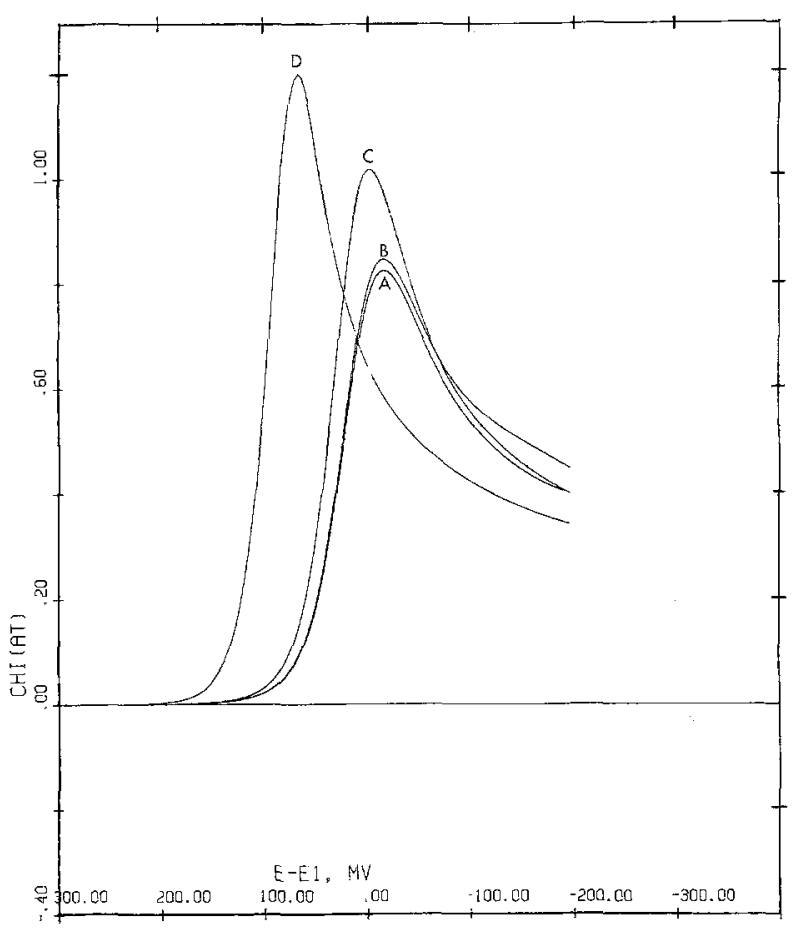

Fig. 7. The simulated cathodic scan for $\lambda_{\mathrm{d}}=10$, and $\Delta \boldsymbol{E}_{\mathrm{BC}}$ equal to (a) $-100 \mathrm{mV}$; (b) $-50 \mathrm{mV}$; (c) 0 ; (d) $+75 \mathrm{mV}$.

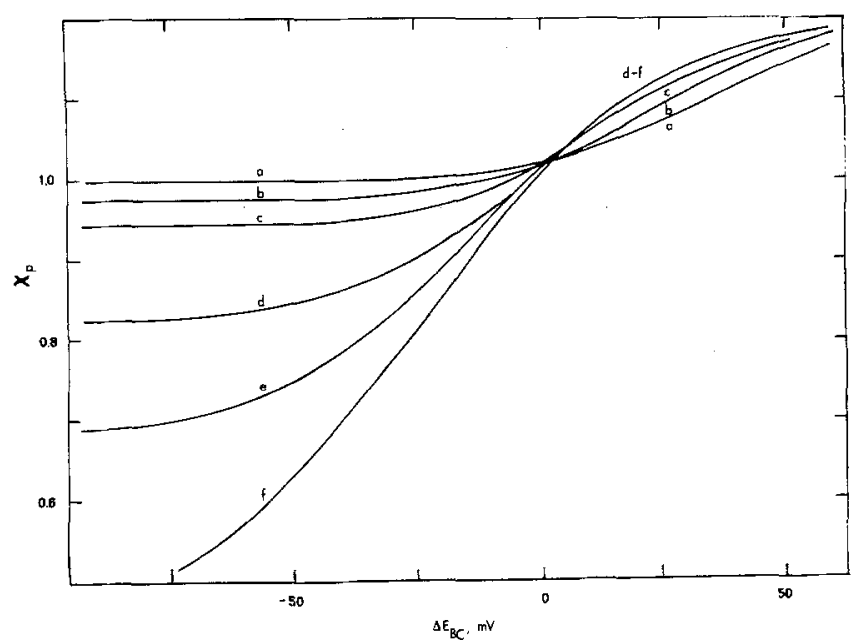

Fig. 8. The variation of $\chi_{\mathrm{p}}$ as a function of $\Delta E_{\mathrm{BC}}$ for various values of $\lambda_{d}$ (second-electron transfer irreversible). (a) $\lambda_{d}=1000$; (b) $\lambda_{\mathrm{d}}=300$; (c) $\lambda_{\mathrm{d}}=100$; (d) $\lambda_{\mathrm{d}}=30$; (e) $\lambda_{\mathrm{d}}=10$; (f) $\lambda_{\mathrm{d}}=\mathbf{0 . 1}$.

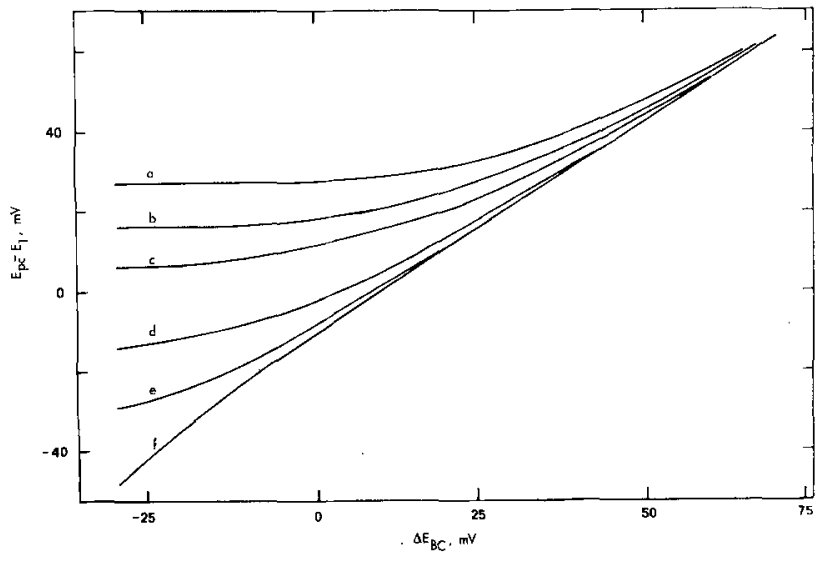

Fig. 9. The variation of $E_{\mathrm{pc}}-E_{1}$ as a function of $\Delta E_{\mathrm{BC}}$ for various values of $\lambda_{\mathrm{d}}$. Volues of $\lambda_{\mathrm{d}}$ given in Fig. 2.

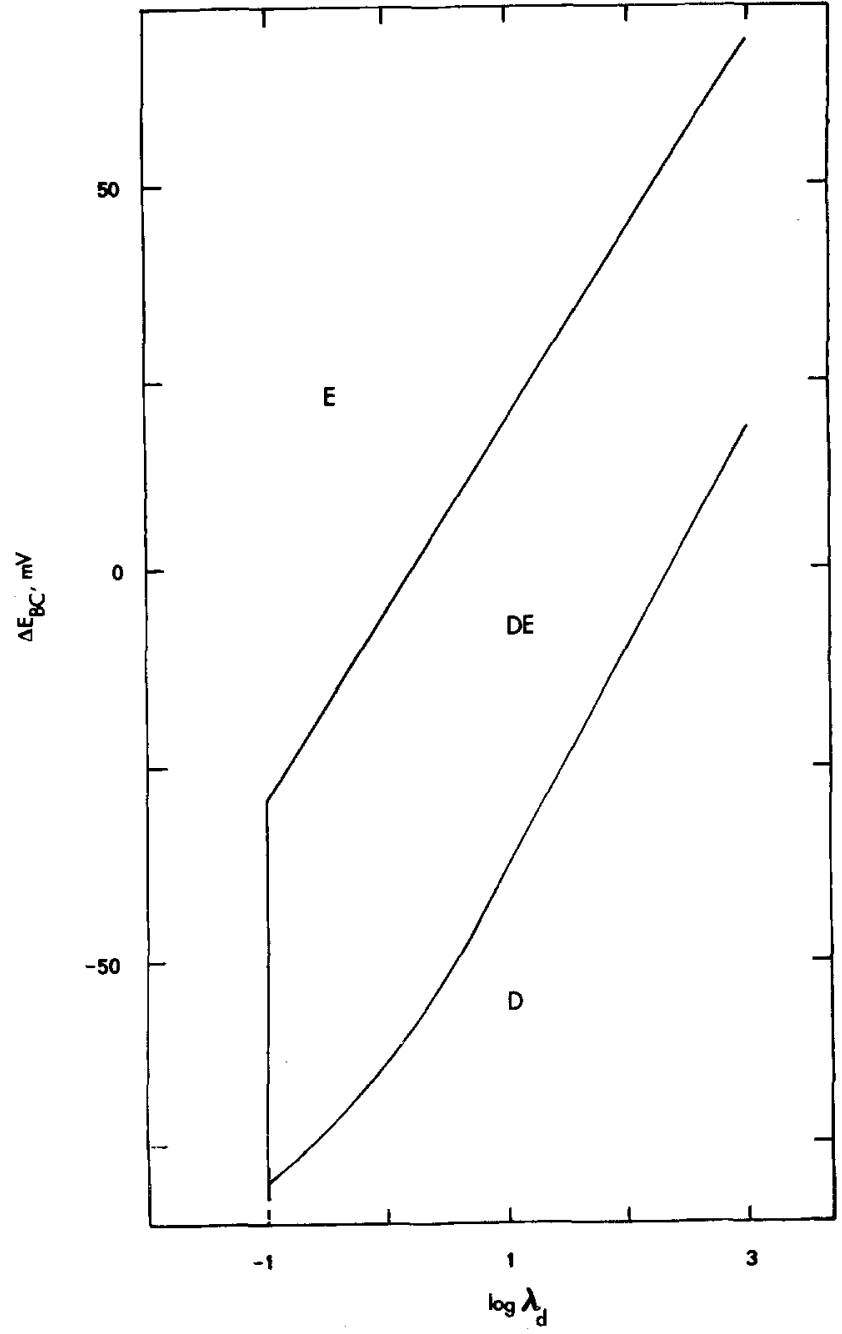

Fig. 10. Values of $\Delta E_{\mathrm{BC}}$ and $\lambda_{d}$ where various mechanisms are applicable. $\mathbf{E}=\mathrm{EE}$ Mechanism, $\mathrm{D}=$ DISP Mechanism, $\mathrm{DE}=$ Mixture of EE, and DISP Mechonism.

reversible $\left(\psi_{2}^{\prime}<0.1\right)$. For quasireversible and reversible waves, the effect of the DISP mechanism is small. Using the criteria that the DISP mechanism predominates if $\chi_{\mathrm{p}}$ is within $5 \%$ of the value for the wave when $\psi_{2}^{\prime}=0$, a range of $\Delta E_{\mathrm{BC}}$ values can be calculated and the results are shown in Fig. 10. At the other extreme, the wave is defined by the $\mathbf{E E}$ mechanism if the $E_{\mathrm{pc}}$ value is within $2 \mathrm{mV}$ of the value obtained when $\lambda_{\mathrm{d}}=$ 0 . These values are also shown in Fig. 10. Between these two limits, the wave is controlled by both the EE and DISP mechanism and Fig. 8 and 9 can be used. These limits can be expressed as follows

DISP mechanism predominates if

$$
\Delta E_{\mathrm{BC}}<25 \log \lambda_{\mathrm{d}}-70 \mathrm{mV}
$$

EE mechanism predominates if

$$
\Delta E_{\mathrm{BC}}>25 \log \lambda_{\mathrm{d}}-5 \mathrm{mV}
$$

While these results were obtained for $\alpha_{2}=0.5$, the same conclusions were obtained for $\alpha_{2}=0.35$ and 0.65 . The $E_{\mathrm{pc}}$ curve shown in Fig. 9 is almost independent of $\alpha_{2}$. The $\chi_{\mathrm{p}}$ curve (Fig. 8) does depend upon $\alpha_{2}$ because the limiting value of $\chi_{\mathrm{p}}$ when $\Delta E_{\mathrm{BC}}$ is large does depend upon $\alpha_{2}$. In general, this dependence is small and varies by only $10 \%$, at most, for $\alpha_{2}$ between 0.35 and 0.65 . But the limits given by Eq. [45] do not depend upon $\alpha_{2}$. This can be seen in Fig. 11 for $\alpha_{2}=0.35,0.5$, and 0.65 and $\lambda_{d}=10$.

\section{Diagnostic Criteria and Data Analysis}

The key to the analysis of cyclic voltammetric data for this case is a systematic approach. The analysis can 


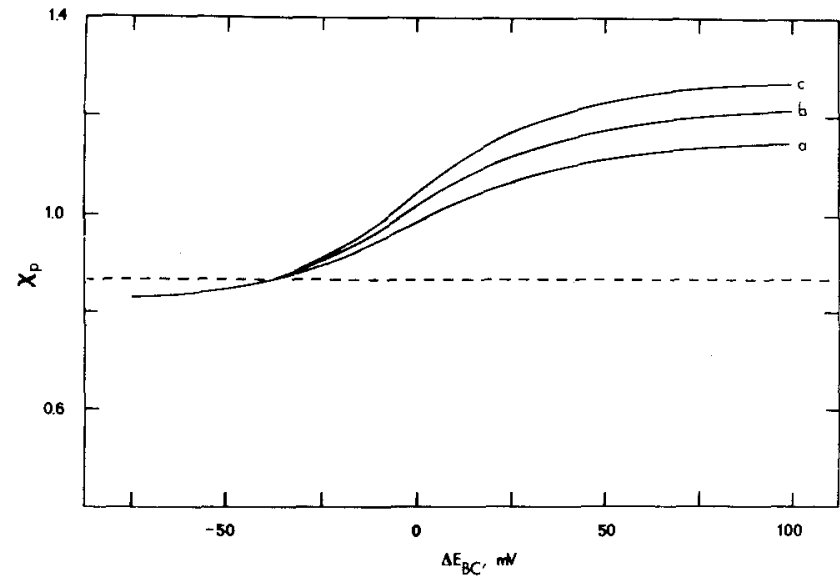

Fig. 11. Variation of $\chi_{\mathrm{p}}$ as a function of $\Delta E_{\mathrm{BC}}$ for $\lambda_{\mathrm{d}}=10$ and $\alpha_{2}$ equal to (a) 0.35 ; (b) 0.50 ; and (c) 0.65 . Dashed line indicates the value where $\chi_{\mathrm{p}}$ has increased by $5 \%$.

be segregated into the following steps:

1. determination that EE mechanism is occurring

2. determine if disproportionation is occurring

3. determination of the reversibility of electron transfer

4. identification of the slow step

5. calculation of electron transfer parameters

Step 1.-The determination that an EE mechanism is occurring is most easily done by double-potential step chronoamperometry. By comparison of the diffusion current with compounds of known electrochemical behavior, the $n$ value can be calculated. Second, from the $i_{\mathrm{a}} / i_{\mathrm{c}}$ ratio, the stability of the product can be verified and one can verify that no irreversible chemical reactions are occurring. Third, the $i_{\mathrm{c}} \sqrt{t} / C_{\mathrm{A}}{ }^{*}$ value should be constant, indicating that no new electroactive products are formed. The value of the final potential must be negative enough so that the slow electron transfer step does not affect the $i_{\mathrm{c}} \sqrt{t} / C_{\mathrm{A}}$ * value.

Step 2.- Since the value of $\lambda_{\mathrm{d}}$ depends upon $C_{\mathrm{A}}{ }^{*}$, the shape and position of the wave should be dependent upon $C_{A}{ }^{*}$. Conversely, $\psi^{\prime}$ is independent of $C_{A}{ }^{*}$, so one can determine if disproportionation is important under the conditions used.

Step 3.-If the shape or position of the wave is independent of scan rate, then the electron transfers are reversible. If the values of $\Delta E_{\mathrm{p}}$ are between 30 and 150 $\mathrm{mV}$, at least one of the electron transfers is slow and the wave is quasireversible. If the $\Delta E_{\mathrm{p}}$ values are greater than $150 \mathrm{mV}$, the electron transfer is irreversible.

Step 4.-The identity of the slow step can be surmised from several ways depending upon the rate of the electron transfers. If the wave is quasireversible, it is difficult to determine the slow step because of the similarities in working curves. Only if scan rates large enough so that $\psi^{\prime}$ is $<0.1$, (i.e., the wave is irreversible) are used can one determine which step is slow.

If the electron transfer is irreversible, the identity of the slow step can be easily determined from the ratio of the peak currents, $i_{\mathrm{p}, \mathrm{a}} / i_{\mathrm{p}, \mathrm{c}}$, where $i_{\mathrm{p}, \mathrm{a}}$ is measured from a baseline calculated from the $t^{-1 / 2}$ decay of the cathodic current. If the first step is slow, then from Eq. [12] and [34]

$\begin{array}{ccc}\text { Since } \alpha_{1}<1 & i_{\mathrm{p}, \mathrm{a}} / i_{\mathrm{p}, \mathrm{c}}=\sqrt{\left(2-\alpha_{1}\right) / \alpha_{1}} \\ i_{\mathrm{p}, \mathrm{a}} / i_{\mathrm{p}, \mathrm{c}} & >1\end{array}$

for all values of $\alpha_{1}$. Conversely, if the second electron transfer is slow

$$
i_{\mathrm{p}, \mathrm{a}} / i_{\mathrm{p}, \mathrm{c}}=\sqrt{\left(1-\alpha_{2}\right) /\left(1+\alpha_{2}\right)}
$$

Once again, $\alpha_{2}$ is less than one. Thus

$$
i_{\mathrm{p}, \mathrm{a}} / i_{\mathrm{p}, \mathrm{c}}<1
$$

Substitution of typical values of $\alpha$ into Eq. [47] or [49] will show that there will be significant deviations from unity for the peak current ratio. In order to use this criterion with confidence, $\psi^{\prime}$ should be less than $0.1\left(\Delta E_{\mathrm{p}}>150 \mathrm{mV}\right)$ and reduced product must be stable.

Step 5.-The calculation of the parameters related to the electron transfer can now be determined once the previous steps have been completed. If the wave is reversible, only the $E_{1,2}$ value can be determined for sure. If $\Delta E$ is less than $180 \mathrm{mV}, E_{1}$ and $E_{2}$ can also be found. If the wave is quasireversible, then $\psi^{\prime}$ and $E_{1,2}$ can be calculated. Once again, if $\Delta E$ is less than $180 \mathrm{mV}$, $E_{1}$ and $E_{2}$ can also be found. If scan rates large enough to make the wave irreversible are used, $\alpha$ can be determined (and hence $\psi$ if $E_{1}$ and $E_{2}$ are known). If the wave is irreversible, $\alpha$ can be calculated from the shape or shift in the wave and ' $\psi^{\prime}$ can be calculated from the $\Delta E_{\mathrm{p}}$ values. Finally, $E_{1,2}$ can be found. If the values of $\Delta E_{\mathrm{AB}}$ or $\Delta E_{\mathrm{BC}}$ are appropriate, then $E_{1}, E_{2}$, and $\psi$ can be found. In all this analysis, it is assumed that the other electron transfer remains reversible. This, in practice, limits the maximum scan rates which can be used to analyze the data by this method.

\section{Results and Conclusions}

The reduction of benzil $(\mathrm{Bn})$ in $0.10 \mathrm{~F}$ barium perchlorate with DMF as solvent is a two-electron quasireversible electron transfer. The cyclic voltammetric data for this solution is shown in Table III. Using the criteria discussed earlier, single and double step chronoamperometry verified that the reduction was a two-electron transfer for times at least as short as 1 msec and that the reduction product was stable. The second step in the analysis was to vary the concentration of benzil to determine if disproportionation was occurring. It was found that for $C_{B n}$ equal to 0.75 and $5.0 \mathrm{mM}$ no change in the shape of the wave was observed $(6)$. Thus, one could analyze the data in Table III without including the disproportionation reaction. The third step is to determine the reversibility of the electron transfer. Since $\Delta E_{\mathrm{p}}$ is greater than $150 \mathrm{mV}$ for all scan rates studied, the electron transfer is irreversible. Finally, because the $i_{\mathrm{p}, \mathrm{a}} / i_{\mathrm{p}, \mathrm{c}}$ ratios are much less than 1.0, the second electron transfer must be the slow step.

For the data below $1 \mathrm{~V} / \mathrm{sec}$, the experimental data fits quite well with the theory for an EE mechanism. From the $\Delta E_{\mathrm{p}}$ values, it was possible to find $\alpha_{2}$, which is equal to 0.66. Equation [39], [41] and [42] can then be expressed in the following manner

$$
\begin{gathered}
\log \psi_{2}^{\prime}=-4.78\left(\Delta E_{\mathrm{p}}+0.021\right) \\
E_{1,2}=E_{\mathrm{pc}}+0.0355\left(0.355-\log \psi_{2}^{\prime}\right) \\
\Delta E=2\left(\Delta E_{\mathrm{BC}}-0.0355 \log \psi_{2}^{\prime}\right)
\end{gathered}
$$

The results obtained by these equations are shown in Table IV. Using these values as estimates, it was possible to generate theoretical voltammograms and compare them with the experimental data. This is shown in Fig. 12 for benzil at $100 \mathrm{mV} / \mathrm{sec}$. The best values given in Table IV are obtained from the best fits of

Table III. Cyclic voltammetry of $0.75 \mathrm{mM}$ benzil in DMF containing $0.10 \mathrm{~F} \mathrm{Ba}\left(\mathrm{ClO}_{4}\right)_{2}$

\begin{tabular}{cccc}
\hline $\mathrm{V}(\mathrm{V} / \mathrm{sec})$ & $E_{\mathrm{pc}}$ & $\Delta E_{\mathrm{p}}(\mathrm{mV})$ & $E_{\mathrm{pp} / 2}(\mathrm{mV})$ \\
\hline 0.05 & -1.419 & 156 & \\
0.1 & -1.428 & 190 & 39 \\
0.2 & -1.438 & 221 & 44 \\
0.5 & -1.448 & 260 & 54 \\
1.0 & -1.457 & $\mathbf{2 8 5}$ & 61 \\
$\mathbf{5 . 0}$ & -1.477 & 365 & 63 \\
10.0 & -1.500 & & 68 \\
20.0 & -1.528 & & 58 \\
\hline
\end{tabular}

* V vs. SRE (silver reference electrode). 
Table IV. Determination of second-electron transfer rate in $0.1 \mathrm{~F} \mathrm{Ba}\left(\mathrm{ClO}_{4}\right)_{2}$

\begin{tabular}{|c|c|c|c|c|c|c|}
\hline $\mathbf{V}(\mathrm{V} / \mathrm{sec})$ & $\frac{\Delta E_{\mathrm{BC}}}{(\mathrm{mV})}$ & $\psi^{\prime}$ & $E_{1}$ & $\underset{(\mathrm{mV})}{\Delta E}$ & $\underset{\left(\mathbf{M}^{-1}\right)}{\mathbf{K}}$ & $\begin{array}{c}k_{\mathrm{s}, \mathrm{a}} \\
(\mathrm{cm} / \mathrm{sec})\end{array}$ \\
\hline $\begin{array}{l}0.05 \\
0.1 \\
0.2 \\
0.5 \\
\text { Best value } \\
\text { Ref. (6) }\end{array}$ & $\begin{array}{r}0 \\
-12 \\
-18 \\
-26\end{array}$ & $\begin{array}{l}0.143 \\
0.0983 \\
0.0699 \\
0.0455\end{array}$ & $\begin{array}{l}-1.407 \\
-1.404 \\
-1.412 \\
-1.410 \\
-1.408 \\
-1.415\end{array}$ & $\begin{array}{r}60 \\
48 \\
46 \\
43 \\
55 \\
100\end{array}$ & $\begin{array}{r}1200 \\
1350 \\
1000 \\
1060 \\
1150 \\
880\end{array}$ & $\begin{array}{l}5.5 \times 10^{-4} \\
5.0 \times 10^{-4} \\
4.9 \times 10^{-4} \\
5.0 \times 10^{-4} \\
5.0 \times 10^{-1} \\
5 \times 10^{-4}\end{array}$ \\
\hline
\end{tabular}

- V vs, SRE.

the experimental data with the simulated voltammograms.

There occur significant deviations at scan rates above $1 \mathrm{~V} / \mathrm{sec}$ due to the slow rate of the first electron transfer. The values of $k_{\mathrm{s}, 1}$ and $\alpha_{1}$ were determined by digital simulation, using the values already calculated for the second electron transfer. It was found that $\alpha_{1}$ was equal to 0.7 , and $k_{\mathrm{s}, 1}$ was equal to $6.5 \times 10^{-3} \mathrm{~cm} / \mathrm{sec}$. The experimental data along with the theoretical curves are shown in Fig. 13 for the $E_{\text {pp } / 2}$ values. An experimental voltammogram with the simulated wave is shown in Fig. 14 for benzil at $1.0 \mathrm{~V} / \mathrm{sec}$.

The rate of the first electron transfer appears to be unusually slow when compared to the rate of reduction with tetrabutylammonium perchlorate (TBAP) as a supporting electrolyte. But once again we are dealing with an apparent electron transfer rate constant, $k_{\mathrm{s}, 1^{*}}$,

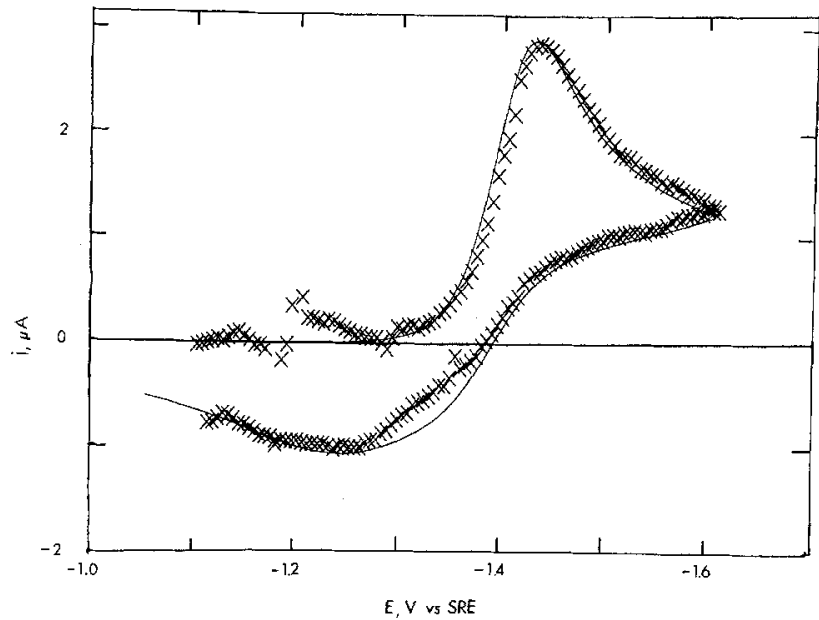

Fig. 12. Cyclic voltammogram for the reduction of $0.75 \mathrm{mM}$ benzil in DMF with $0.10 \mathrm{~F} \mathrm{Ba}\left(\mathrm{ClO}_{4}\right)_{2}$. Scan rate $=100 \mathrm{mV} / \mathrm{sec}$; solid line, theoretical; $x$, experimental points.

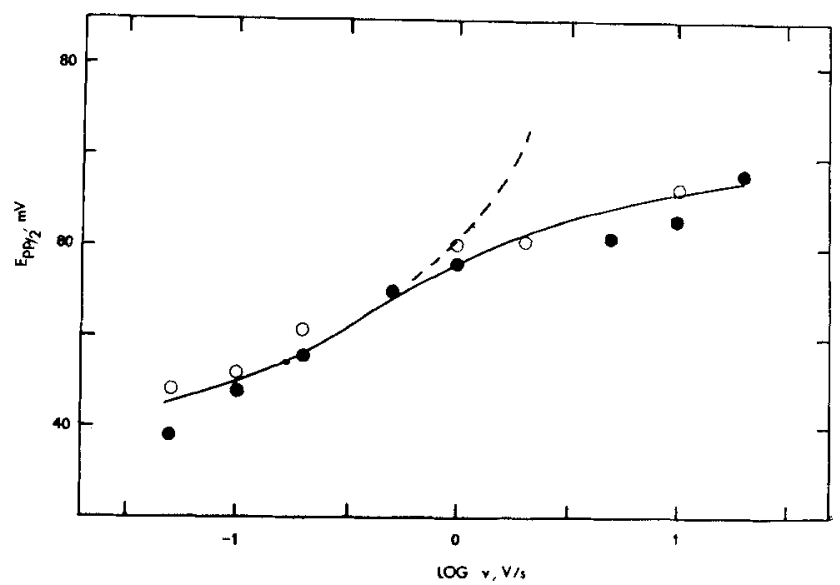

Fig. 13. The variation of $E_{\mathrm{pp} / 2}$ as a function of scan rate. Solid line, $k_{\mathrm{s}, 1}=0.10 \mathrm{~cm} / \mathrm{sec}, \alpha_{1}=0.7, k_{8,2}=5.0 \times 10^{-4} \mathrm{~cm} / \mathrm{sec}$, $\alpha_{2}=0.66$; dashed line, first-electron transfer reversible; closed circles, $C_{B n}=0.75 \mathrm{mM}$; open eircles, $C_{B n}=5.0 \mathrm{mM}$.

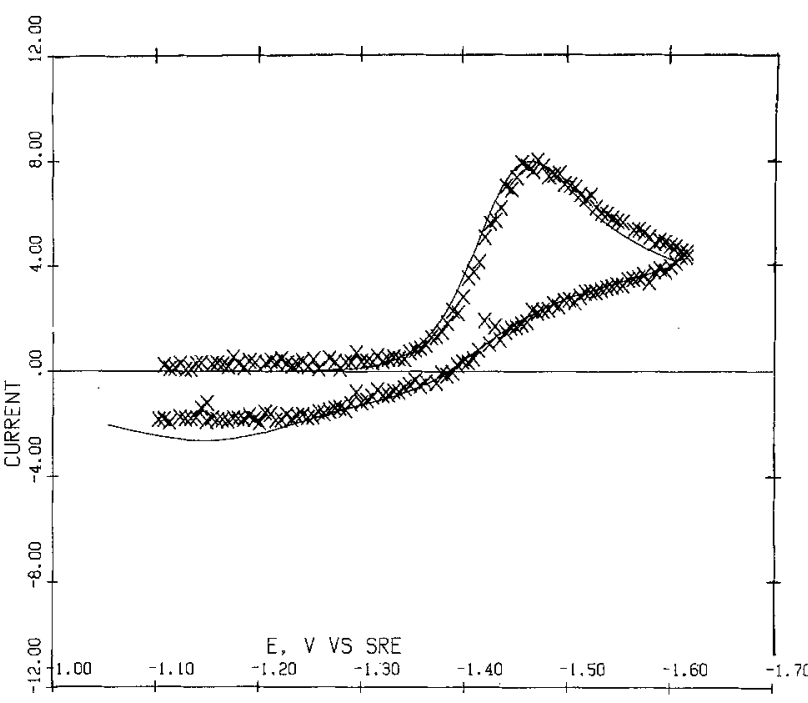

Fig. 14. Cyelic voltammogram for the reduction of $0.75 \mathrm{mM}$ benzil in DMF with $0.10 \mathrm{~F} \mathrm{Ba}\left(\mathrm{ClO}_{4}\right)_{2}$. Scan rate $=1 \mathrm{~V} / \mathrm{sec}$; solid line, theoretical; $x$, experimental points.

instead of the true $k_{\mathrm{s}, 1}$. This is caused by the shift of the benzil

$$
\begin{gathered}
\mathrm{Bn}+e \rightleftharpoons \mathrm{Bn} \cdot \\
\mathrm{Bn}^{\top}+\mathrm{Ba}^{2} \stackrel{\mathrm{K}}{\rightleftharpoons} \mathrm{BnBa}
\end{gathered}
$$

reduction from its equilibrium position being due to the ion-pairing reaction. Since the wave occurs positive of the potential where benzil alone is reduced, the heterogeneous forward rate constant, $k_{\mathrm{hf}}$, at the peak potential is less than $k_{\mathrm{s}, 1}$ due to the exponential relationship between $k_{\mathrm{hf}}$ and $k_{\mathrm{s}, 1}$

$$
k_{\mathrm{hf}}=k_{s, 1} \exp \left[-\alpha_{1} \frac{n F}{R T}\left(E-E^{\circ}\right)\right]
$$

If one solves the boundary value problem for the above reaction, it turns out that $k_{\mathrm{s}, 1}$ * is related to $k_{\mathrm{s}, 1}$ by the following equation

$$
k_{\mathrm{s}, 1}=k_{\mathrm{s}, 1} *\left(1+\mathrm{KC}_{\mathrm{Ba}}\right) \alpha_{1}
$$

where $\mathrm{C}_{\mathrm{Ba}}$ is the concentration of the barium ion. For $\mathrm{KC}_{\mathrm{Ba}}=115$ and $\alpha_{1}=0.7, k_{\mathrm{s}, 1}$ is $0.18 \mathrm{~cm} / \mathrm{sec}$. This value of $k_{\mathrm{s}, 1}$ is within the range that has been observed for several quinones recently (12). This value is still smaller than the minimum value estimated in the presence of TBAP only. This difference cannot be due to ion pairing between the barium and perchlorate ions. While this will reduce $\left[\mathrm{Ba}^{2+}\right]$, it will at the same time increase the value of $\mathrm{K}$ because the $\mathrm{K}\left[\mathrm{Ba}^{2+}\right]$ value was observed experimentally. In addition, estimations of the $\mathrm{Ba}-\mathrm{ClO}_{4}$ ion pair constant from Bjerrum's theory (13) and from data for $\mathrm{Mg}_{-} \mathrm{ClO}_{4}$ in acetonitrile and acetone (14) indicate that ion pairing of the barium perchlorate electrolyte is insignificant in DMF. This lower rate constant could be due, though, to double layer changes caused by the presence of barium ions.

Using the information in Table IV, it is possible to estimate the maximum value for the disproportionation rate constant, $k_{\mathrm{d}}$, using Eq. [45]. The maximum value of $k_{\mathrm{d}}$ depends upon scan rate, with the disproportionation reaction being more important at faster scan rates because $\Delta E_{B C}$ is decreasing. For $C_{B n}=0.75$ $\mathrm{mM}$, it was found that $k_{\mathrm{d}}$ must be less than $700 \mathrm{M}^{-1}$ $\mathrm{sec}^{-1}$. This maximum value may be too small to see. A more practical value is probably $3 \times 10^{3} \mathrm{M}^{-1} \mathrm{sec}^{-1}$. Since no disproportionation reaction is seen for the $5 \mathrm{mM}$ solution, $k_{\mathrm{d}}$ must be less than $750 \mathrm{M}^{-1} \mathrm{sec}^{-1}$. It is interesting to note that if $\psi_{2}^{\prime}$ were zero, a value of $k_{\mathrm{d}}=750 \mathrm{M}^{-1} \mathrm{sec}^{-1}$ could be easily seen and calculated. Thus, for $\mathrm{C}_{\mathrm{Bn}}=5 \mathrm{mM}$ and $v=50 \mathrm{mV} / \mathrm{sec} ; \lambda_{d}$ 
would be 2.7. But this reaction, if it occurs, is obscured by the second electron transfer.

The determination of $k_{\mathrm{s}, 2}$ for the reduction of benzil in the presence of strontium ion can be accomplished in the same way. The $\alpha_{2}$ value was again found to be 0.65. Thus, Eq. [47]- [49] could be used. The results are shown in Table V. The calculated values for the benzil reduction with the strontium ion present agree well with the values determined by trial-and-error simulation. As was seen before (6), the second-electron transfer is somewhat slower with the strontium ion pair than with the barium ion pair. This difference, though, could be due to double layer effects.

The simplicity of this method of analysis is quite evident. Previously, it was necessary to perform a considerable number of trial and error simulations before the best fit could be obtained in order to determine the electron transfer parameters for the $\mathrm{EE}$ mechanism. But by use of the equations given in the paper, it was possible to directly calculate the parameters. A second advantage is that it is possible to identify significant deviations from the EE mechanism, as was shown in this case for scan rates in excess of $1 \mathrm{~V} / \mathrm{sec}$ with barium ions present. If an EE mechanism is occurring with only one of the $k_{s}$ values being slow, the shape of the wave should follow the criteria given previously. In particular, a good diagnostic criteria is the shift in the anodic and cathodic peak potentials with scan rates. Consistent $\alpha$ values should be obtained from these calculations. A factor complicating the analysis is the situation where both electron transfers may be slow. The diagnostic criteria will obey qualitatively the analysis given in this paper, but will fail seriously upon quantitative analysis. Work is in prog-

Table V. Cyclic voltammetry of benzil in DMF containing $0.10 \mathrm{Fr}\left(\mathrm{ClO}_{4}\right)_{2}$

\begin{tabular}{lcccccc}
\hline V (V/sec) & $\begin{array}{c}E_{\mathrm{pp} / 2} \\
(\mathrm{mV})\end{array}$ & $\begin{array}{c}\Delta E_{\mathrm{p}} \\
(\mathrm{mV})\end{array}$ & $E_{1} *$ & $\begin{array}{c}\Delta E \\
(\mathrm{mV})\end{array}$ & $\begin{array}{c}k_{\mathrm{n}, 2} \\
(\mathrm{~cm} / \mathrm{sec})\end{array}$ & $\begin{array}{c}\mathrm{K} \\
\left(\mathrm{M}^{-1}\right)\end{array}$ \\
\hline 0.05 & 47 & 285 & -1.372 & 72 & $1.4 \times 10^{-4}$ & 4800 \\
0.1 & 49 & 322 & -1.370 & 76 & $1.4 \times 10^{-4}$ & $\mathbf{5 1 4 0}$ \\
0.5 & 58 & 350 & -1.383 & 80 & $1.7 \times 10^{-4}$ & 3100 \\
Best value & & & -1.375 & 80 & $1.6 \times 10^{-4}$ & 4300 \\
Ref. (6) & & & -1.397 & 135 & $2.0 \times 10^{-4}$ & 1800 \\
\hline
\end{tabular}

- V vs. SRE. ress in this laboratory to present similar methods for the analysis of this case.

\section{Acknowledgment}

This research was supported by the Petroleum Research Fund, administered by the American Chemical Society. I would also thank Dennis Evans for his help. In addition, the Computer Services Division of Marquette is acknowledged for providing computer time for this work.

Manuscript submitted April 11, 1977; revised manuscript received Oct. 31, 1977.

Any discussion of this paper will appear in a Discussion Section to be published in the December 1978 Journal. All discussions for the December 1978 Discussion Section should be submitted by Aug. 1, 1978.

Publication costs of this article were assisted by Petroleum Research fund.

\section{REFERENCES}

1. D. S. Polcyn and I. Shain, Anal. Chem., 38, 370 (1966).

2. R. L. Myers and I. Shain, ibid., 41, 980 (1969).

3. I. Ruzic, J. Electroanal. Chem., 52, 331 (1974).

4. R. S. Nicholson, Anal. Chem., 37, 1351 (1965).

5. M. Mastragostino, L. Nadjo, and J. M. Saveant, Electrochimica Acta, 13, 721 (1968).

6. M. D. Ryan and D. H. Evans, J. Electroanal. Chem., 67, 333 (1976) ; W. H. Smith and A. J. Bard, ibid., 76. 19 (1977).

7. V. Gutmann, M. Michlmayr, and G. Peychal-Heiling, J. Electroanal. Chem., 17, 153 (1968).

8. S. W. Feldberg in "Electroanalytical Chemistry," Vol. 3, A. J. Bard, Editor, pp. 199-296, Marcel Dekker, Inc., New York (1969).

9. S. W. Feldberg, in "Electrochemistry," J. S. Mattson, H. B. Mark, Jr., and H. C. McDonald, Jr., Editors, pp. 185-215, Marcel Dekker, Inc., New York (1972).

10. D. M. Mohliner, J. Phys. Chem., 68, 623 (1964).

11. R. S. Nicholson and I. Shain, Anal. Chem., 36, 706 (1964).

12. T. W. Rosanske and D. H. Evans, J. Electroanal. Chem., 72, 277 (1976).

13. J. O'M. Bockris and A. K. N. Reddy, "Modern Electrochemistry," p. 265, Plenum Press, New York (1973).

14. I. S. Perehygin and M. A. Klimchuk, Russ. J. Phys. Chem. (Engl. Transl.), 47, 1402 (1973); ibid., 48, 1466 (1974). 